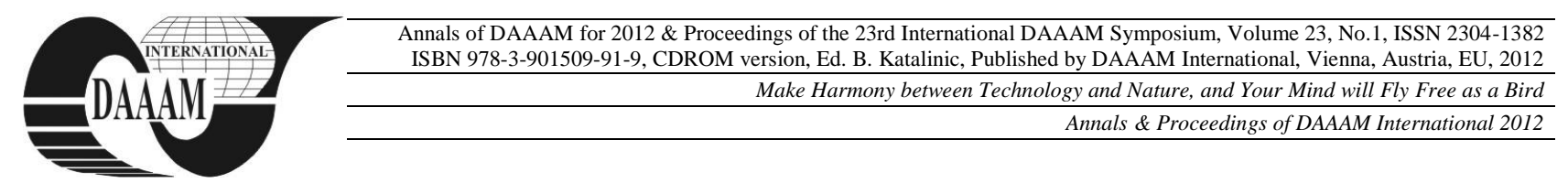

\title{
INFLUENCE OF RENEWABLE ENERGY ON POWER TRANSFORMER INSULATING SYSTEM
}

\author{
KRPAL, O[ndrej]; SIRUCEK, M[artin] \& MRAZ, P[etr]
}

\begin{abstract}
Electricity represents an integral part of the infrastructure of countries and also forms an integral part of life for all people. Transmission of electrical energy to the final consumer is relized by using electricity grid. This can be divided into two main parts: transmission and distribution. In both parts there are a lot of electrical and electrnic components which might be are under electrical stress and harmfully influenc insulation of the devices. This paper talks about higher stress caused by connection of renewable sources.

Keywords: renewable energy, pulses stress, electrical degredation, transformer insulating system, partial discharges
\end{abstract}

\section{INTRODUCTION}

Today's electricity system is a complex system, composed of set of electrical and electronic components. Each of these elements is the resulting set of more or less significant influence. Elements of the system can be divided into primary and secondary. Among the primary elements belong transformers, lightning arresters, surge arresters, circuit breakers, disconnectors etc. The secondary group includes a variety of electronic information and protective systems which are used for local or remote control, monitoring and regulation of certain elements. Undoubtedly the most important part of the transmission and distribution power system includes transformers. These ensure first transfer of power between the required voltages levels - low voltage (LV), high voltage (MV) and high voltage (HV) and are an important element allows considerable savings in energy transfer over long distances. The main reason for the deployment of transformers and high-voltage networks in transmission electricity is called Joule limitation losses, which are proportional to the resistance line (given by the physical properties of wires) and the square of the current. As transmitted power is proportional to a transmitted voltage and current, "Simple" increasing voltage while keeping the transmitted power will reduce Joule losses four times. This was the fundamental reason for beginning to use AC - the possibility of voltage transformation.

Based on the location and use of the transformers can be divided as to the distribution and block. Distribution transformers are used in transmission system to transform the voltage between the voltage and power levels range from tens to hundreds of kVA MVA.
The second group consists of the block (power) transformers, which are located near the production site power. Performance-then correspond to a power source.

An important part of transformers from the point of functionality and reliability is the tap changer, which allows control of both transformer taps and flexible response to changes in the network (voltage regulation). Other, more detailed division of transformers is based on their classification according to rated power: small (500 $\mathrm{kVA}$ to $7500 \mathrm{kVA})$, medium ( $7500 \mathrm{kVA}$ to $100 \mathrm{MVA})$ and large (100 MVA and above). From this view, the large power transformers at the same time crucial and financially costly power system equipment.

Reliability and service life of transformers is significantly influenced by the quality of the insulating system. It has to achieve stable properties especially the effect of various degradation factors, which is the device during their lifetime. It is also necessary to ensure that the resulting system was cost-effective. From this reason, in practice there are two-component insulating systems. The first component (solid) is usually represented by cellulose-based material, the second part represents the electrical fluid, which in most cases is inhibited transformer oil is mostly mineral origin.

\section{RENWEABLE SOURCES}

A new trend in the field of energy in the long term utilization resources is the use of renewable resources, meaning for example the energy hydro, wind, solar and geothermal. Using the electricity produced by renewable energy sources mentioned above no harmful emissions appear, and thus such resources do not contribute to greenhouse gases. Slows the depletion of non-renewable resources and also helps the formation new job opportunities.

Currently share of electricity energy primarily from photovoltaic and wind power plants still growing. This increase is apparent for example in Spain, Denmark, Italy, and especially in Germany, where the local government is preparing in 2022 to shut down all nuclear power plants and this shortfall in production will try to replace just by the production of renewable sources. It is assumed that the transmission network surely notices several changes associated with this energy policy. 
Czech Republic joining the EU committed itself in 2010 to manufacture from alternative sources covering $8 \%$ of production and by 2020 this proportion rises to $13.5 \%$.

\subsection{Solar Energy}

Energy from the sun can be used in several ways. Currently, the most widespread energy production using solar panels with a photovoltaic phenomenon and solar radiation is directly converted into electrical energy. The amount of produced energy is then influenced by the intensity of solar radiation in the location and time that the radiation falls on the surface of the panel. In the Czech Republic this length is around 1,500 hours per year and that determins load factor of solar panels at $7 \%$. This coefficient indicates the utilization of the installed capacity. In other words, when has an energy source on the load factor at $20 \%$, i.e. that one-fifth of this resource runs at $100 \%$ of rated output and for the rest of his output is then zero.

Another possible use of solar radiation is concentrated solar power (CSP), when the sun's rays reflected from parabolic mirrors and focused on an oil receiver. Then heat is converted to steam in a central heat exchanger. The steam is used in a conventional steam turbine. The advantage of this technology is more stable production power even in the moments when the sun disappears behind a cloud thanks heat accumulation. Moreover, it can be solar heating combined heat heating with fossil fuels, gas or biomass.

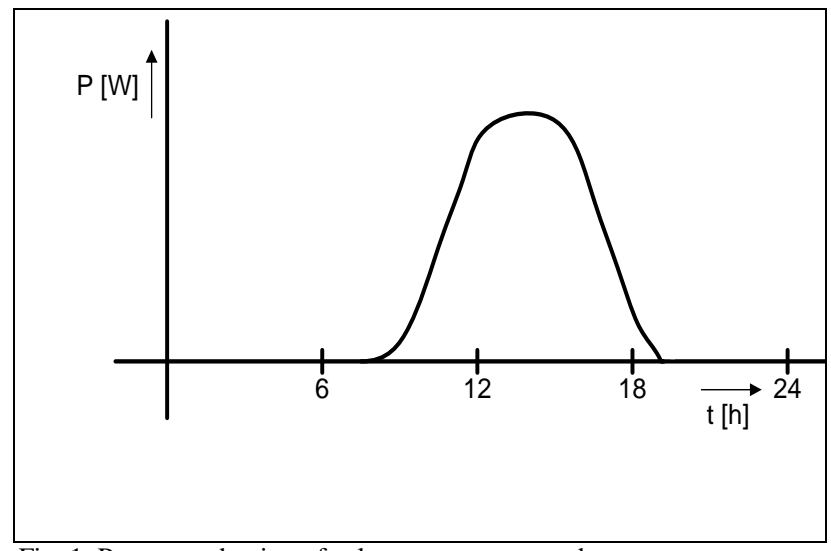

Fig. 1. Power production of solar energy - sunny day

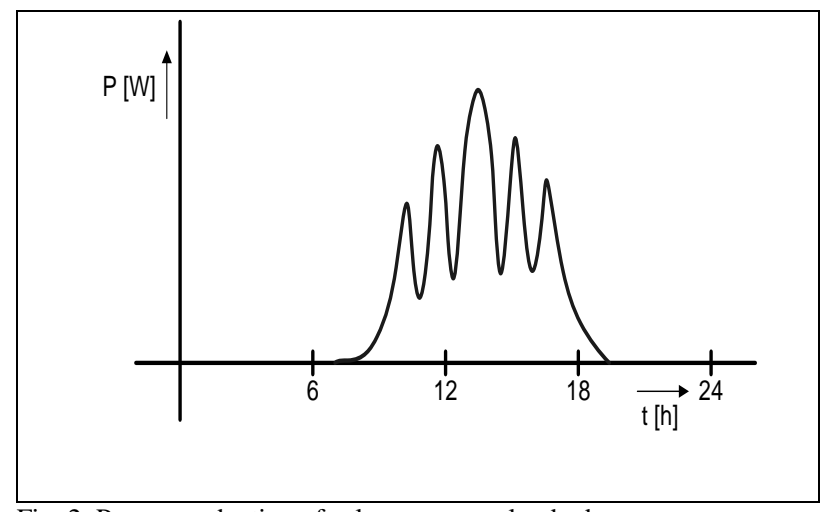

Fig. 2. Power production of solar energy - cloudy day

\subsection{Wind Energy}

For energy derived from wind is also basically solar energy when the sun radiation falls on the earth, which is unevenly heated. This results in to pressure differences in the atmosphere that balances the flowing wind. Then the wind can spin the blades of wind turbines and power over the shaft generator.

Turbines are distinguished with vertical and horizontal axis. Turbines with vertical axis are not so widespread. Their advantage is lower acceleration rate, independence on wind direction and the possibility of easy transfer of torque to the ground. The disadvantage is a lower output power, up to $50 \%$ less than in the case of turbines with a horizontal axis. This second type has a shaft parallel to the surface of the earth and the generator is located at the top of the mast. Turbines are depended on the direction of wind flow, so they are equipped by a sensor for finding optimal rotation turbine.

Production (output) of each turbine is described by the power curve (Power curve - Fig. 3). It shows the dependence of the energy produced on the speed of flowing wind. On this curve so called acceleration rate is marked (cut inspeed), describing the wind speed at which turbine begins producing power energy. Mostly, this value is between $3-5 \mathrm{~m} / \mathrm{s}$. The rated turbine output is another point on the curve at rated speed - in other words, the lowest possible wind speed at which the turbine achieves maximum power. The last figure shows the power curve maximum wind speed in which it is possible to operate the wind turbine (Cutoff speed). After reaching this value the turbine must be stoped to prevent its destruction.

Grouping several turbines in the same location can constitute wind farm, which can cover an area of several hundred square meters. Currently, the largest wind farm is located in Roscoe (Texas) includes 627 wind turbines and its installed capacity reaches 781.5 MW. Today's trend is to install wind turbines located near the coast (offshore windfarms). One of the benefits is higher output power compared with farms located on land, until doubled. It is reported that annual utilization factor for wind farms is around $20 \%$, at a farm located in coastal waters, this number moves about $40 \%$.

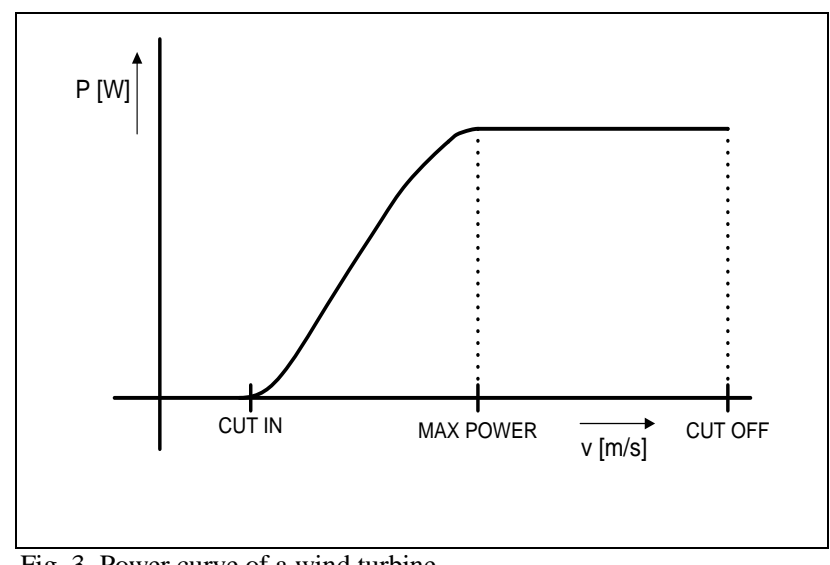




\section{UDESIRABLE EFFECTS OF RENEWABLE ELECTRICITY GRID}

As the number of connected renewable sources to the electricity system rises, so the risk of damage of the insulation system equipment increases. The reason is AC converters used in photovoltaic and wind power plants for converting the DC voltage to AC. AC converter are also used in the latest trend of power transmission using the DC lines. Using the principle of reduced losses in transmission described above, the next restriction transmitting power losses using direct current limiting the AC losses (eg hysteresis, etc.). At present, there are so-called HVDC transformers (High Voltage Direct Current) used for direct transmission of electrical energy. In the past, this option was not possible for high power for the absence of switching components for the high power and so high voltage. HVDC networks are successfully used for example in Australia, Norway, China and the Netherlands and in Europe are also planned, mainly because of the transfer of energy from renewable sources over long distances. Currently this transfer causes considerable problems in the European electricity grid.

A negative aspect of the inverters is particularly different deformation of sinusoidal voltage (called harmonics) and the possible of short-term surge pulses generation. Introduced deformations depend on steps of inverter. Electrical overvoltage according to their size then causes increasing the frequency of occurrence of partial discharges and thus undesirable local thermal, mechanical and chemical degradation. In case of enough significant exceedance of insulating system design, even thermal insulator breakdown occurs. Therefore, the transformers must struggle with that.

Another important factor is the variability in energy supply network which causes big problems for transmission and distribution systems. A production of conventional sources must adapt production of renewable energy. Variability of electricity supply causes changes in the size and direction of the energy flow in the system and this creates a problem with the control of the system from the point of power transmission, but also in the point of voltage regulation. The system voltage control reacts on the fluctuations in energy consumption which changes as a result of the voltage drop in dependance on the size of the transmitted current. Regulating transformers in the electricity grid can compensate the voltage by switching the taps. While in the network with conventional energy sources such regulation occurs in the order of up to several tens of switching transformer taps per day, in the network where the power source with the variation of output power is included (Solar or wind power), this number growths significantly!

Another disadvantage is that the renewable sources are connected to the electricity network especially in places which are not designed for the back deliver to the network.
For the future, there are planned connections of an increasing number of renewable sources. This means greater demands to the transmission system and the transformers themselves. It should also be solve the problem of storage of energy from renewable resources, which means probably build new pumped-storage power plants in areas with differences in height and transfer of "renewable" energy to these places.

\section{IMAPCT OF PARTIAL DICHARGES TO THE INSULATION MATERIALS}

The discharges in dielectric systems have usually four basic negative impacts electrical, thermal, chemical and erosive impact.

If inside the cavity is air, during the discharges there is produced ozone $\mathrm{O} 3$ and carbon dioxide $\mathrm{CO} 2$, these gases cause intensive oxidation effects. Next degradation effects are caused by various acids which are products of dissociation of insulation. Also the ions and electrons, which bombard walls of cavity, support gradual degradation of insulation.

\subsection{Electrical impacts}

By the impact of partial discharges, an electric spark can arise in cavity, this usually lead to formation of conductive track. Provided the sufficient high voltage, electrical field at the end of conductive track can cause electrical breakdown and conductive track cam spread to the rest of the dielectric system.

\subsection{Chemical impacts}

Chemical impacts arise during the longer (in the meaning of time) partial discharge activity. The main degradation factors are ozone, carbon dioxide, hydroxide nitrogen and hydrogen in the matter of origination. These arise like a product of partial discharge activity. During the chemical reactions within the dielectric system solid, liquid and gas products arise. It has deep negative impact especially for organic insulations, where disintegration and shrinkage of material occur.

Solid products arise after longer time period, in the meaning of hours. They have a form of crystals and they contain correspond to oxalic acid. Crystals are caused by a cluster of droplets, which occur during PD activity together with oxygen, carbon and hydrogen.

Garci's research team was engaged to observing of gas products of PD activity. They have proved that carbon monoxides, dioxides and small amount of hydrogen are presented inside the insulation. Research was done with XLPE (Cross-Linked Polyethylene) material by gas chromatography. After that they observe electrical treeing as well. Spectroscopy method was used and presence of carbon oxides and small amount of hydrogen was found.

In the same research liquid products were found as well. They were in the form of small droplets located on the surface of the material. In the test atmosphere was 
required presence of carbon monoxides and water, but it is according to gas products of PD activity. Droplets had a shape of simple organic chemical compounds - acetic acid and formic acid. Liquid products make an increase of surface conductibility of cavities. It is caused all these components are dissolving and combining with water and it makes electrolytic layer.

\subsection{Thermal impacts}

Straight result of PD activity could be thermal instability because dielectric system under the influence of PD activity increases its temperature and because of that thermal breakdown voltage decreases.

Interesting results are given by researches of Mr. Di Lorenzo del Casele and Mr. Schifani, who have tested the impact of temperature to air cavity in epoxy resins. In temperature interval from $30{ }^{\circ} \mathrm{C}$ to $80{ }^{\circ} \mathrm{C}$ the lifetime period of resins increases. The main cause of that was the softening of resin, which reduce bombarding of resin surface by particles. Further they found out that the temperature has significant influence to repetition of partial discharges. It was decreased because of resin conductivity reduction. Increased surface conductivity lead to reduction of electrical field intensity inside the air gaps and it leads to lower repetition of PDs.

\subsection{Erosive impacts}

Erosive impacts are caused partial discharges which bombarding walls of cavities by ions and degrade them. In the case of intensive influence of erosion mechanical or electrical breakdown of dielectric can occur.

\section{EXPERIMENT}

The reliability of electrical energy supply depends on quality of transmission and distribution networks. The significant influence on the reliability has also the specific electrical equipments used for them. Due to different effects during the running conditions the systems operate not only with the alternating currents (AC) but also with pulses. Therefore the insulating systems must have an appropriate electrical strength on these different shapes of the electrical signals to endure the thermal stress.

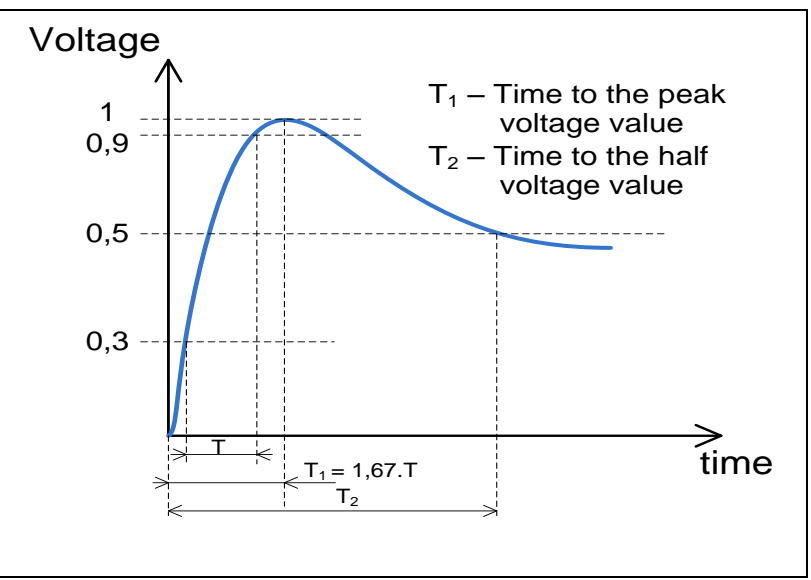

Fig. 4. Parameters of voltage impulse
The aim of the paper is to specify influence of an electrical and a thermal stress on the insulation lifetime. The experiment consists of an electrical degradation of oil-paper insulation under AC and pulse voltage. The insulation is usually used especially in power transformers, current and voltage transformers and in different types of power electrical equipments e.g. bushings, cables.

Nowadays, the research in the field of insulation liquids is focused on environmental friendly oils. Therefore the normal mineral oil is compared to the perspective oil based on natural esters.

The insulating system of transformers is exposed during its running conditions to various degradation factors. They have a significant influence on the equipment lifetime. Individual degradation mechanisms are together closely linked and cause deterioration of electrical and non-electrical parameters of the system. The basic factors of degradation are electrical, thermal and mechanical stress. These factors together with the time cause a chemical degradation. It represents a decomposition of structure of the system or creates compounds of gaseous, liquid and solid products.

In the case of electrical degradation are not important only stress by the normal sinusoidal shape of voltage and current, but also stress due to current and voltage pulses. Their duration may be very short for example in the order tens of nanoseconds. Therefore they measurement could be difficult. Also a value of pulse amplitude is usually higher, than the limits of the system due to designing.

\subsection{Electrical degradation by impulse voltage}

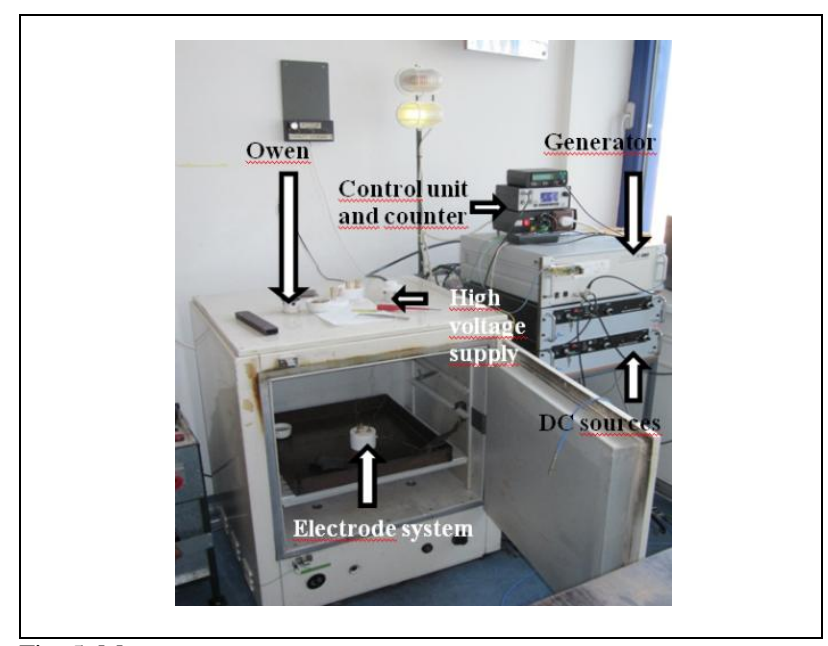

Fig. 5. Measurement setup

Electrical stress was caused by short voltage pulses. They had leading edge $90 \mathrm{~ns}$ (measured between $10 \%$ and $90 \%$ of peak voltage value) and frequency of $10 \mathrm{kHz}$ at a temperature of $30{ }^{\circ} \mathrm{C}$ and $70{ }^{\circ} \mathrm{C}$ The samples were made from thermal upgrade paper 22 HCC Dennison with dimension $0.08 \mathrm{~mm} \times 2.5 \mathrm{~mm}$. Preparation of samples consists of two steps. The first was dried 48 hours at temperature $45{ }^{\circ} \mathrm{C}$ which is sufficient for the small 
samples. The second step was impregnation by mineral oil DIALA DX in the same condition as the first step. Impregnated samples were carried out in a small reactor made from Polytetrafluorethylen. The three measuring brass electrodes with diameter $10 \mathrm{~mm}$ were placed in the electrode system filled with Diala DX. The electrode system laid during the electrical stress in the oven HERAUS with a temperature range of $30{ }^{\circ} \mathrm{C}$ to $200{ }^{\circ} \mathrm{C}$. The test pulses were created in generator PVX 4110 from DEI. The DC voltage supplied two sources TECHNIX with a maximum value of peak voltage $\pm 5 \mathrm{kV}$.

Leading edge is limited during measurement by maximum load power $\mathbf{P}$ of the generator. The $\mathbf{P}$ depends on parameters according equation (1). $\mathbf{C}$ is the total size of the maximum capacity, including power cables, load capacity, the internal capacity of the generator the sample capacity and therefore dimension of the sample. The size $\mathbf{U}$ determines the value of pulse voltage. Frequency $\mathbf{f}$ indicates the repetition rate of pulses per second.

$$
P=C \cdot U^{2} \cdot f(\mathrm{~W} ; \mathrm{F}, \mathrm{V}, \mathrm{Hz})
$$

Lead time was determined by function on a digital oscilloscope AGILENT 54853 INFINIUM DSO as an increase between $10 \%$ and $90 \%$ of the peak voltage value (Fig. 6). Times of breakdown were measured for each sample. Six samples that mean two sets were broken on the each voltage values. The voltage value applied on the samples was increasing than the breakdown within 5 minutes occurred. After this the voltage value was decreasing with step $0.1 \mathrm{kV}$. If the first set of samples had small difference in the breakdown times compared with set measured before, the voltage was again reduced about 0.1 $\mathrm{kV}$.

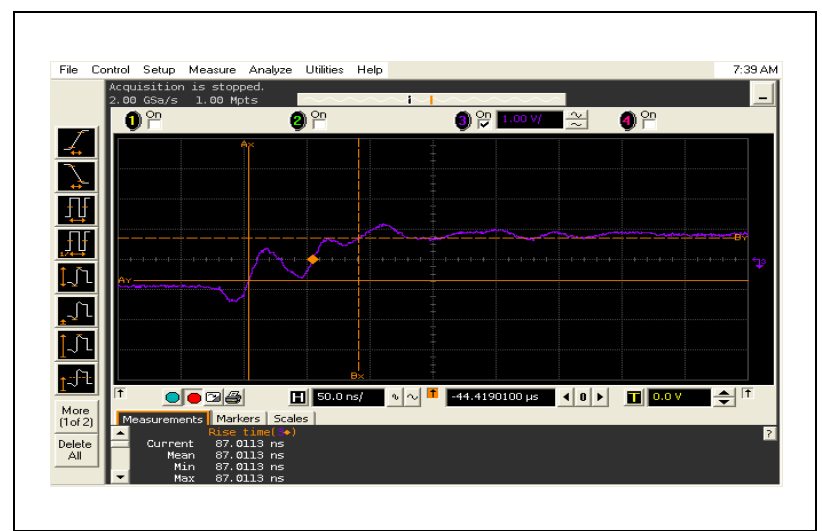

Fig. 6. The shape of voltage testing pulse

The measured results of the breakdown times were evaluated by model commonly used for electrical degradation. It is an exponential model (2) and power regression model (3). Where $t$ is the time of life in hours, the electric field $\mathrm{E}$ and $\mathrm{n}, \mathrm{a}$ and $\mathrm{b}$ are constants determined empirically. They are general aging models that describe the degradation due to external fields acting.

$$
t=k \cdot E^{-n}\left(\mathrm{~h} ; \mathrm{kV} \cdot \mathrm{mm}^{-1},-\right)
$$

$$
t=a \cdot e^{-b E}\left(\mathrm{~h} ;-,-, \mathrm{kV} \cdot \mathrm{mm}^{-1}\right)
$$

These relationships are empirically determined models. They are validity only for a certain range of the electric field. Lower values of the electric field have not almost any effect on the electrical degradation of the insulating systems.

In Fig. 7 is shown the comparison of results for the pulse degradation for a temperature $30{ }^{\circ} \mathrm{C}$ and $70{ }^{\circ} \mathrm{C}$ in Diala DX oil. The approximation of curves by the exponential model was done.

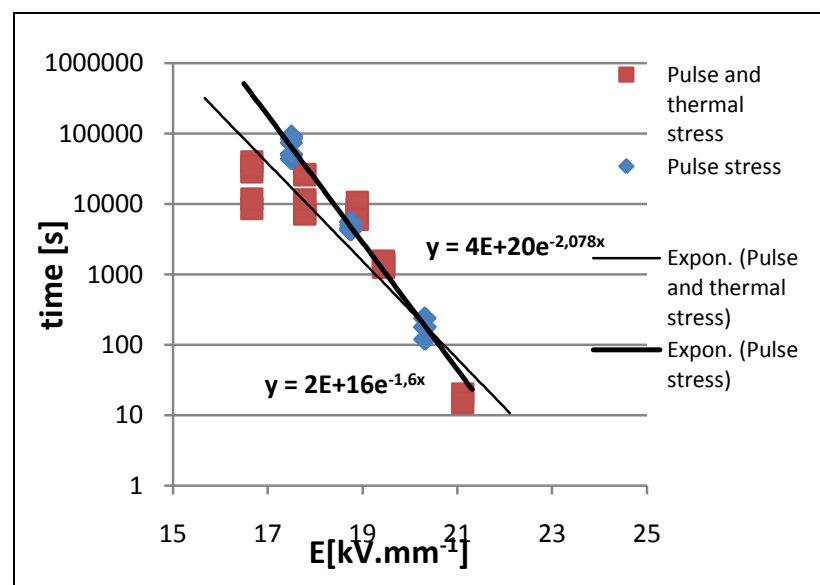

Fig. 7. Influence of temperature on insulating system samples lifetime

The results of breakdown voltage times for both temperatures are not very different. The most significant differences were seen at lower voltages. On the results of breakdown times for density of electric field above 20kV.mm ${ }^{-1}$ had not temperature almost any effect. Therefore the differences between the values of breakdown times for both models of aging were approximately $100 \mathrm{~s}$. The parameters calculation of the power and exponential regression models are presented in Tab. 1

\begin{tabular}{|c|c|c|c|c|}
\hline Description & \multicolumn{2}{|c|}{ Exponential model } & \multicolumn{2}{c|}{ Power model } \\
\hline Parameter & $\mathrm{k}$ & $\mathrm{n}$ & $\mathrm{a}$ & $\mathrm{b}$ \\
\hline $\begin{array}{c}\text { Pulse stress } \\
\text { Pulse and } \\
\text { thermal } \\
\text { stress }\end{array}$ & $2,00 \mathrm{E}+20$ & $-2,08$ & $4,00 \mathrm{E}+53$ & $-39,24$ \\
\hline
\end{tabular}

Tab. 1.Values of parameters of exponential and power regression models

The Fig. 8 shows the pulse and a sinusoidal stresses measured at room temperature. Aging models presented in Tab. 1 have the greatest accuracy in the region where practical measurement was done. For the pulse stress was the region in the range $16 \div 21 \mathrm{kV} . \mathrm{mm}^{-1}$ and for sinusoidal in the range $20 \div 40 \mathrm{kV} \cdot \mathrm{mm}^{-1}$. Pulse stress had steeper curve and faster time of breakdown at a lower intensity of the electric field in accordance with the theoretical 
assumptions. Practical application of the influence of the electric field on the lifetime of the insulation system is show in Tab. 2. The results are presented for the intensity $20 \mathrm{kV} \cdot \mathrm{mm}^{-1}$. Time specified by the exponential regression model is marked as $t_{\text {expo }}$ of the power and $t_{\text {power }}$.

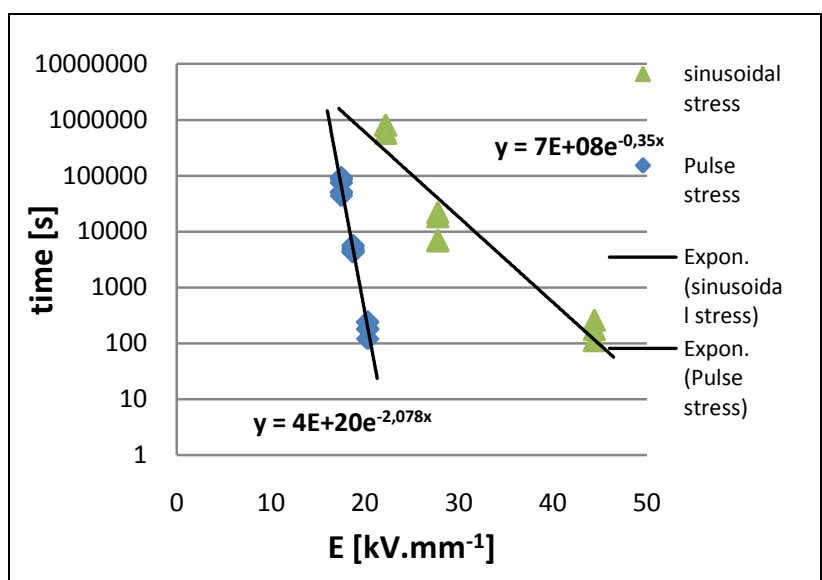

Fig. 8. Influence of sinusoidal and pulse stress on insulating system samples lifetime

\begin{tabular}{|c|c|c|c|c|c|c|}
\hline \multirow{2}{*}{$\begin{array}{c}\text { E } \\
{\left[\mathrm{kV} . \mathrm{mm}^{-1}\right]}\end{array}$} & \multicolumn{2}{|c|}{ Sinusoidal } & \multicolumn{2}{c|}{ Pulse } & \multicolumn{2}{c|}{$\begin{array}{c}\text { Pulse and } \\
\text { thermal }\end{array}$} \\
\cline { 2 - 7 } & $\begin{array}{c}\mathrm{t}_{\exp } \\
{[\mathrm{h}]}\end{array}$ & $\begin{array}{c}\mathrm{t}_{\text {power }} \\
{[\mathrm{h}]}\end{array}$ & $\begin{array}{c}\mathrm{t}_{\exp } \\
{[\mathrm{h}]}\end{array}$ & $\begin{array}{c}\mathrm{t}_{\text {power }} \\
{[\mathrm{h}]}\end{array}$ & $\begin{array}{c}\mathrm{t}_{\exp } \\
{[\mathrm{h}]}\end{array}$ & $\begin{array}{c}\mathrm{t}_{\text {power }} \\
{[\mathrm{h}]}\end{array}$ \\
\hline \multirow{2}{*}{20} & 1,77 & 3,76 & 9,92 & 9,85 & 7,04 & 8,57 \\
& $\mathrm{E}+02$ & $\mathrm{E}+02$ & $\mathrm{E}-02$ & $\mathrm{E}-02$ & $\mathrm{E}-02$ & $\mathrm{E}-02$ \\
\hline
\end{tabular}

Tab. 2. Example of application of the regression model for time of breakdown calculation for electric field $20 \mathrm{kV} \cdot \mathrm{mm}^{-1}$

\section{CONCLUSIONS}

The results achieved in the experiments show the significant influence of pulse degradation on the reduction of lifetime of oil-paper insulating system. The time to breakdown in the case of sinusoidal electric stress have about four orders higher lifetime for the same electric field than pulse stress. Thermal degradation $70^{\circ} \mathrm{C}$ haven't almost any influence on time to the breakdown differences. Therefore measured times and they regression models closely correlated.

\section{ACKNOWLEDGEMENTS}

This work was supported by the Student Grant Agency of the West Bohemia University in Pilsen, grant No. SGS-2012-026 "Material and Technology Systems in Electrical Engineering“"

\section{REFERENCES}

[1] HARLOW, James H. Electric power transformerengineering. USA : CRCPress, 2007. 388 s. ISBN 0-8493-1704-5

[2] RIBEIRO, Cacilda de Jesus, et al. Faults and Defects in Power Transformers - A Case Study. In 2009 IEEE Electrical Insulation Conference .Montreal : IEEE, 2009. s. 142-145

[3] SPARLING, Brian ; AUBIN, Jacques. Determination of Health Index for Aging Transformers in View of Substration Asset Optimization. In Proceedings of the 2010 International Conference on Condition Monitoring an Diagnosis : Modern Asset Management Technology for green operation. 2010. Tokyo, Japan : Institute of Electrical Engineers of Japan, 2010. s. 73-77. ISBN 978-4-88686-070-5

[4] Global Market Outlook for Photovoltaics until 2015. In: [online]. 2011 [cit. 2012-08-06]. Available from: http://www.epia.org/publications/photovoltaic-publicationsglobal-market-outlook.html

[5] Delivering Offshore Wind Power in Europe: POLICY RECOMMENDATIONS FOR LARGE-SCALE DEPLOYMENT OF OFFSHORE WIND POWER IN EUROPE BY 2020. In: [online]. 2007 [cit. 2012-08-10]. Available from: http://www.ewea.org/fileadmin/ewea_documents/images/publicati ons/offshore_report/ewea-offshore_report.pdf

[6] WERNER, M. a K. LOPPACH. The Electrical Testing of Transformers for High-Voltage Direct Current Transmission. In: Highvolt Kolloquium '11. Dresden: HighvoltPruftechnik Dresden GmbH, 2011, s. 65-70

[7] BP Statistical World Energy Review 2011, retrieved 8 August 2011

[8] Renewable energy sources. In: [online]. [cit. 2012-08-10]. Available from: http://www.alternativni-zdroje.cz/

[9] VÁPENÍK, René. Influence of photovoltaic power plants on the operation of distribution. Elektrorevue [online]. 2011, roč. 12, č. 1 [cit. 2012-03-06]. ISSN 1213-1539. Available from: http://www.elektrorevue.cz/cz/clanky/energetika--vykonovaelektronika--elektrotechnologie/10/vliv-fotovoltaickychelektraren-na-provoz-distribucni-soustavy/

[10] Veverka, Antonín. The technique of high voltage. Second realse. Prague : SNTL - Nakladatelství technické literatury, 1978. 295 s.

[11] Záliš, Karel. Partial discharge in insulation systems of electrical machines. Vyd. 1. Prague : Academia, 2005. 140 s. ISBN 80-2001358-X

[12] Mentlík, Václav, et al. Diagnosis of electrical equipment. 1. edition. Prague : BEN - technická literatura, 2008. 439 s. ISBN 978-80-7300-232-9

[13] Píša, Miroslav. Deterioration of epoxy resins by discharge activities. Pilsen, 2006. 33 s. Bachelor thesis. ZČU, FEL 